\title{
Pengaruh Digital Marketing Mobile Application Terhadap Loyalitas Pelanggan Gojek
}

\author{
Aulia Millatina Lisani dan Indrawati \\ Universitas Telkom Bandung \\ Email:lauliamillatina@gmail.com dan indrawati02@gmail.com
}

Diterima: Juni;Dipublikasikan:Juli 2020

\begin{abstract}
ABSTRAK
Dari perkembangan teknologi serta di dukung oleh gaya hidup masyarakat sehingga dapat mempengaruhi kecepatan dalam penyebaran suatu informasi melalui media sosial dan dimanfaatkan sebagai media baru dalam memasarkan suatu produk atau disebut pemasaran digital (digital marketing). Digital marketing dapat digunakan sebagai sarana untuk menginformasikan atau memberikan edukasi kepada konsumen terhadap suatu produk atau merek sehingga konsumen menjadikan konsumen lebih loyal terhadap merek atau produk. Penelitian ini memiliki tujuan untuk mengetahui apakah terdapat pengaruh Digital Marketing Mobile Application terhadap Loyalitas Pelanggan pada layanan yang dimiliki oleh Gojek secara simultan ataupun parsial. Penelitian yang dilakukan menggunakan metode kuantitatif. Variabel-variabel yang dianalisis adalah interactive, incentive programs, site design dan transaction/cost sebagai variabel independen, dan loyalitas oelanggan sebagai variabel dependen. Untuk pengumpulan data, peneliti menggunakan kuesioner secara online melalui googleform dengan jumlah responden sebanyak 400 orang. Teknik sampling yang digunakan yaitu purposive sampling dan metode pengumpulan data dengan kuesioner (Skala Likert) dan studi kepustakaan. Teknik analisis data yang dilakukan melalui model analisis Structural Equation Modellung (SEM) yang di olah dengan bantuan aplikasi SmartPLS 3.0.
\end{abstract}

Kata Kunci: internet, digital marketing, loyalitas pelanggan, aplikasi

\begin{abstract}
From the development of technology and supported by people's lifestyles so that it can affect the speed in the dissemination of information through social media and is used as new media in marketing a product or called digital marketing. Digital marketing can be used as a means to inform or provide education to consumers of a product or brand so that consumers make consumers more loyal to the brand or product. This study aims to determine whether there is an influence of Digital Marketing Mobile Application on Customer Loyalty on the services owned by Gojek simultaneously or partially. Research conducted using quantitative methods. The variables analyzed are interactive, incentive programs, site design and transaction / cost as independent variables, and customer loyalty as the dependent variable. For data collection, researchers used an online questionnaire through Googleform with a total of 400 respondents. The sampling technique used is purposive sampling and data collection methods with a questionnaire (Likert Scale) and literature study. Data analysis techniques were carried out through the Structural Equation Modellung (SEM) analysis model, which was processed with the help of the SmartPLS 3.0 application.
\end{abstract}

Keywords: internet, digital marketing, costumer loyalty, application

\section{PENDAHULUAN}

Kegiatan yang dilakukan masyarakat Indonesia tidak jauh dari unsur teknologi dan unsur digital. Kegiatan mulai dari keseharian, pendidikan, hingga bisnis kini berubah. Tranksaksi global pun berjalan seakan tidak ada sekat perbedaan negara dan geografi. Pertumbuuhan Gojek sangatlah pesat sejak aplikasi ini meluncur, data yang didapatkan menyebutkan bahwa pengguna aktif Gojek menurut penelitian mencapai hampir 22 juta pengguna per bulan [1]. Menurut CNBC Indonesia pendapatan Gojek adalah $\$ 10$ Milliar sampai saat ini, hal ini terjadi salah satunya adalah karena Gojek melakukan promosi yang menarik. Bagi suatu perusahaan, media promosi sangat berpengaruh terhadap penjualan, promosi dapat memberikan informasi untuk menarik perhatian konsumen dan selanjutnya akan memberikan pengaruh pada meningkatnya penjualan [2]. Dalam pemasaran aplikasi mobile (mobile apps) mempunyai banyak manfaat salah satunya adalah dapat mempermudah pelanggannya untuk mendapatkan produk atau jasa melalui perangkat mobile dan mendapatkan informasi terkait suatu produk dan jasa. Tujuan dari penelitin ini adalah 1) untuk mengetahui penilaian responden terhadap variabel interactive, incentive programs, site design dan 
transaction/cost pada pelanggan Gojek, 2) Untuk mengetahui tingkat loyalitas pelanggan Gojek, 3) Untuk mengetahui pengaruh interactive, incentive programs, site design dan transaction/cost berpengaruh terhadap loyalitas pelanggan Gojek, 4) Untuk mengetahui model yang diusulkan dapat digunakan untuk memprediksi loyalitas pelanggan Gojek.

\section{Digital Marketing}

\section{TINJAUAN PUSTAKA}

Digital marketing adalah kegiatan pemasaran yang pada saat ini yang sangat berpotensi untuk mendapatkan pelanggan secara online, antara lain melalui media internet. Ia juga mengemukakan bahwa digital marketing dapat meningkatkan hubungan dengan pelanggan, digital marketing juga mampu membangun koneksi dengan pelanggan sehingga dapat menargetkan prospek yang baru [3]. Menurut Daniel dan Dyah (2018) terdapat empat dimensi dari variabel digital marketing yang akan menjadi variabel independent pada penelitian ini, antara lain:

a. Interactive

Interactive merupakan hubungan komunikasi dua arah antara pihak perusahaan dan konsumen sehingga bisa diterima dengan baik dan cukup jelas.

b. Incentive programs

Incentive programs merupakan keunggulan program pada promosi yang dilakukan oleh perusahaan sehingga dapat menambah nilai yang lebih kepada perusahaan.

c. Site design

Site design merupakan tampilan yang menarik dapat menambahkan nilai yang positif kepada perusahaan melalui media digital marketing.

d. Transaction/Cost

Transaction/Cost merupakan teknik promosi yang dapat mengefisiensikan waktu dan menekan biaya transaksi.

\section{Loyalitas Pelanggan}

Loyalitas pelanggan didefinisikan sebagai pembelian non-acak yang diungkapkan dari waktu ke waktu oleh beberapa unit pengambilan keputusan. Berdasarkan definisi tersebut menjelaskan bahwa loyalitas mengacu pada perilaku pengambilan keputusan untuk melakukan pembelian secara berulang kepada suatu produk atau jasa. Selanjutnya untuk variabel Y yang merupakan loyalitas pelanggan (Y1), menggunakan teori Griffin dalam Linda dan Sesilya (2016) [4], yang terdiri dari 4 dimensi, antara lain:

1. Makes regular repeat purchase

2. Purchase across product and service lines

3. Refers other

4. Demonstrate an immunity to the full of the competition

\section{Kerangka Pemikiran}

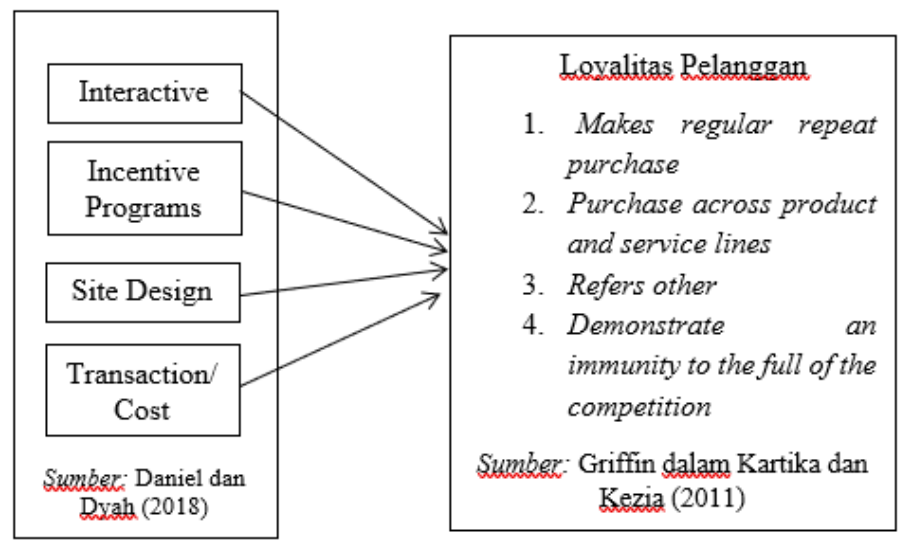

Gambar 2.1 Kerangka Pemikiran 


\section{METODE PENELITIAN}

Metode penelitian ini menggunakan pendekatan kuantitatif dengan jenis penelitian bersifat deskriptif dan kausal. Dalam penelitian ini, peneliti tidak melakukan intervensi data dan waktu di penelitian ini adalah cross sectional. Populasi merupakan keseluruhan kelompok orang, kejadian, benda-benda yang menarik peneliti telaah sehingga populasi yang dipilih oleh peneliti akan menjadi pembatas dari hasil penelitian yang diperoleh . Populasi pada penelitian ini merupakan masyarakat yang menggunakan aplikasi Gojek di kota Bandung, Jabodetabek, Surabaya, Makassar dan Medan. Untuk menentukan sampel peneliti menggunakan rumus Cohcran sehingga dari perhitungan tersebut maka mendapatkan sampel yang digunakan dalam penelitian ini sebanyak 400 responden. Peneliti menggunakan teknik analisis data Structural Equation Modelling (SEM) dengan teknik Partial Least Square (PLS). Partial Least Square adalah analisis persamaan structural yang dapat menguji pengukuran secara simultan dan dapat menguji model strukural secara bersamaan.

\section{HASIL DAN PEMBAHASAN}

Dalam penelitian ini memiliki memiliki lima aspek karakteristik penelitian, yaitu domisili, usia, jenis kelamin, pendidikan terakhir, pekerjaan dan pendapatan. Dari hasil yang didapatkan maka responden yang berdomisili di Bandung 62,5\%, Jabodetabek 11,8\%, Medan 10,5\%, Makassar 8\% dan yang terakhir adalah Surabaya 7,3\%. Dilihat dari jenis kelamin yaitu responden perempuan sebanyak 57,8\% dan laki-laki 42,3\%. Dilihat dari usia 17-25 Tahun sebanyak 84,3\%, 26-35 Tahun 13,3\%, 36-45 Tahun 1,5\% sedangkan usia 46-65 Tahun 1\%. Dilihat dari pendidikan terakhir untuk SMA sekitar 57\%, S1 34,3\%, D3 6,3\% dan yang terakhir adalah S2/S3 2,5\%. Dilihat dari pekerjaan sebagai pelajar/mahasiswa $68 \%$, Karyawan swasta $19,3 \%$, Pengusaha $5 \%$, Pegawai Negeri Sipil 3,3\% dan Lainnya 4,5\%. Dilihat dari pendapataan Rp. <3.000.000 sebanyak 62\%, Rp. $4.005 .000-$ Rp. 5.000.000 18,3\%, Rp. 5.005.000 - Rp. 6.000 .000 sebanyak 9,5\%, Rp. 7.005 .000 - Rp. 8.000 .000 sebanyak 7\%, dan Rp. $\geq 9.000 .000$ sebanyak 3,3\%.

Teknik dalam PLS, dapat dilakukan dengan dua uji model yaitu uji model pengukuran (outer model) dan uji model structural (inner model). Untuk uji outer model dapat dilakukan dengan pengujian validitas dan reliabilitas terhadap indikator yang digunakan dalam penelitian. Suatu penelitian dapat dikatakan baik jika memiliki nilai loading factor $>0,05$ sehingga dapat memenuhi convergent validity. Seluruh variabel dalam penelitian dapat dikatakan baik jika memiliki nilai composite reliability > 0,07 dan nilai Cornbach's alpha >0,60.

Uji inner model dapat mengetahui nilai $R$ square yang didapatkan pada variabel laten endogen dan t-value dari hasil bootsrapping. Berikut adalah hasil uji inner model pada penelitian ini:

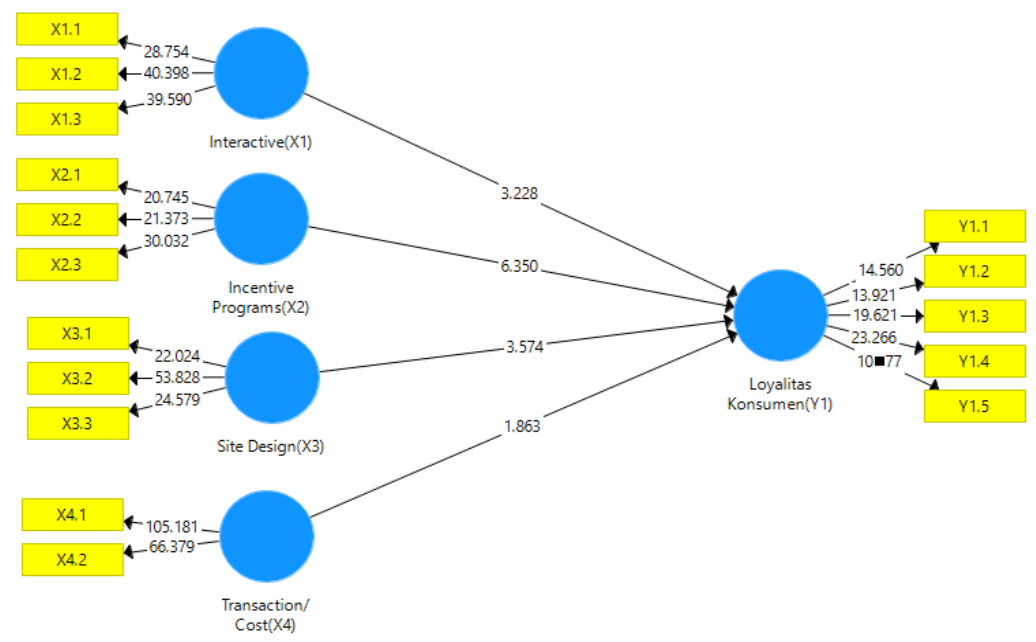

Gambar 3.1 Hasil Uji Inner Model 
Tabel dibawah ini akan menjelaskan hasil yang di dapatkan dari bootstrapping dengan bantuan software SmartPLS:

Tabel 1. Nilai Path Coeffisient dan t-value variabel penelitian

\begin{tabular}{|c|c|c|c|}
\hline Path Diagram & Path Coeffisient & T Value & Kesimpulan \\
\hline $\begin{array}{c}\text { Interactive } \rightarrow \\
\text { Loyalitas Pelanggan }\end{array}$ & 0,160 & 3,228 & H Diterima \\
\hline $\begin{array}{c}\text { Incentive Programs } \\
\rightarrow \text { Loyalitas } \\
\text { Pelanggan }\end{array}$ & 0,297 & 6,350 & H Diterima \\
\hline $\begin{array}{c}\text { Site Design } \rightarrow \\
\text { Loyalitas Pelanggan }\end{array}$ & 0,197 & 3,574 & H Diterima \\
\hline $\begin{array}{c}\text { Transaction/Cost } \rightarrow \\
\text { Loyalitas Pelanggan }\end{array}$ & 0,105 & 1,863 & H Diterima \\
\hline
\end{tabular}

Pengujian hipotesis penelitian ini menggunakan one-tailed test dengan tingkat kesalahan 5\%, sehingga nilai krisis yang harus dipenuhi yaitu 1,65. Berdasarkan hasil yang didapatkan dari Bootsrapping pada tabel 1. sehingga dapat diketahui bahwa seluruh variabel dinyatakan signifikan sehingga hipotesis dapat diterima.

Tabel 2. Nilai R Square

\begin{tabular}{|l|c|}
\hline \multicolumn{1}{|c|}{ Variabel } & R Square \\
\cline { 1 - 1 } Interactive $\rightarrow$ Loyalitas Pelanggan & \\
\cline { 1 - 1 } Incentive Programs $\rightarrow$ Loyalitas Pelanggan & \\
\cline { 1 - 1 } Site Design $\rightarrow$ Loyalitas Pelanggan & \\
\cline { 1 - 1 } Transaction/Cost $\rightarrow$ Loyalitas Pelanggan & \\
\hline
\end{tabular}

Berdasarkan pengolahan data yang dilakukan dengan software Smart PLS, dapat diketahui bahwa koefisien penentuan dari variabel interactive, incentive programs, site design, dan transaction/cost terhadap loyalitas pelanggan adalah sebesar 31,6\%.

\section{Kesimpulan}

\section{KESIMPULAN DAN SARAN}

Berdasarkan hasil penelitian yang telah dilakukan oleh penulis bertujuan untuk mengetahui pengaruh interactive, incentive programs, site design dan transaction/cost terhadap loyalitas pelanggan Gojek. Sehingga, dapat diperoleh kesimpulan sebagai berikut: Interactive pada aplikasi yang dimiliki oleh Gojek berpengaruh secara signifikan terhadap loyalitas pelanggan. Interactive terhadap aplikasi Gojek tergolong dalam tingkatan yang cukup tinggi. Hal tersebut dikarenakan para pelanggan sudah merasa bahwa aplikasi yang dimiliki oleh Gojek cukup komunikatif untuk menyampaikan kritik dan saran. Incentive programs berdampak secara signifikan terhadap loyalitas pelanggan. Incentive programs terhadap aplikasi yang dimiliki oleh Gojek tergolong dalam tingkatan yang tinggi. Hal tersebut dikarenakan para pelanggan merasa insentif berupa promosi yang diberikan oleh perusahaan Gojek kepada konsumen dapat mendorong penggunaan layanan Gojek. Site design berdampak secara signifikan terhadap loyalitas pelanggan Gojek. Site design terhadap aplikasi yang dimiliki oleh Gojek tergolong dalam tingkatan yang cukup tinggi. Hal tersebut dikarenakan para pelanggan merasa tampilan dalam aplikasi mempengaruhi penggunaan dan pemesanan aplikasi Gojek. Transaction/cost berpengaruh signifikan terhadap loyalitas pelanggan. Transaction/cost terhadap aplikasi yang dimiliki oleh Gojek tergolong rendah. Terkait dengan hal ini perusahaan harus lebih meningkatkan kualitas aplikasi yang dimiliki oleh Gojek sehingga konsumen akan merasa lebih nyaman dalam bertransaksi akan lebih meningkatkan sebuah loyalitas pada perusahaan.

\section{Saran}

Faktor pertama incentive programs dirasakan kurang sehingga diharapkan Gojek dapat meningkatkan penawaran diskon dan promosi untuk beberapa layanannya seperti go-food, go-ride, 
go-car, go-send dst guna untuk memenuhi keinginan pelanggan dngan demikian Gojek dapat meningkatkan loyalitas pelanggan.

Faktor kedua adalah site design pentingnya memperhatikan isi dan desain dari sebuah aplikasi, karena aplikasi tersebut adalah sebuah sarana untuk berkomunikasi antara pihak perusahaan dengan konsumen. Hal tersebut perlu diperhatikan dari fasilitas yang akan mendukung fungsi komunikasi tersebut, Gojek perlu memperhatikan desain aplikasi mereka sehingga dapat lebih menarik dan nyaman dilihat dengan memperhatikan tata letak, warna yang di aplikasikan hingga tulisan yang dapat mendukung fungsi aplikasi. Faktor ketiga yaitu interactive, responden merasa bahwa aplikasi Gojek dirasa kurang memiliki fitur untuk menampung kritik yang disampaikan oleh pelanggan, oleh karena itu Gojek harus lebih meningkatkan fitur dalam aplikasi Gojek agar kritik yang disampaikan oleh pelanggan tersampaikan kepada pihak Gojek. Faktor keempat yaitu transaction/cost dapat diketahui bahwa responden merasa promosi yang dilakukan oleh Gojek melalui aplikasinya kurang membantu aktifitas konsumen secara efektif sehingga Gojek dapat lebih meningkatkan kualitas aplikasi agar konsumen merasa nyaman dan aman dalam bertransaksi sehingga menciptakan sebuah loyalitas pelanggan.

\section{DAFTAR PUSTAKA}

Hamdani, L. A. (2019). Gojek Rebranding dan Kalahkan Grab Soal Pengguna Aktif Bulanan. Tek.id. https:// www.tek.id/tek/gojek-rebranding-dan-kalahkan-grab- soal-pengguna-aktif-bulananb1Xj29eZz.

Togodly, E. T. (2019). Pengaruh Promosi Terhadap Peningkatan Penjualan pada Koperasi Serba Usaha Baliem Arabica Di Kabupaten Jaya Wijaya. Media Neliti.

Miller, M. (2018). B2B Digital Marketing. Indianapolis, Indiana: Que.

Imasari, K., \& Kurniawati, K. (2011). PENGARUH CUSTOMER RELATIONSHIP MANAGEMENT

TERHADAP LOYALITAS PELANGGAN PADA PT BCA TBK. Fokus Ekonomi, 183-192.

Indrawati. (2015). Metode Penelitian Manajemen dan Bisnis Konvergensi. Teknologi Komunikasi dan Informasi. Bandung: Aditama.

Abdillah, W. H. (2015). Partial Least Square (PLS). Yogyakarta: Penerbit Andi. 